\title{
A social media-based study on the psychological impact of COVID-19 infections in recovered and recovering patients
}

\section{Vikesh Kumar}

Department of Physical Education (T), Guru Nanak Dev University, Amritsar, Punjab, India

\section{Mohit Varshney}

Consultant Psychiatry, ILBS, New Delhi, India

Harmandeep Singh ( $\square$ harmankamboj91@gmail.com )

Department of Physical Education, Apeejay College of Fine Arts, Jalandhar, Punjab, India https://orcid.org/0000-0003-0997-7777

\section{Amandeep Singh}

Department of Physical Education (T), Guru Nanak Dev University, Amritsar, Punjab, India Julien S. Baker

Department of Sport, Physical Education and Health, Hong Kong Baptist University: Kowloon Tong, Hong Kong

\section{Research Article}

Keywords: anxiety, depression, COVID-19, social, media

Posted Date: October 22nd, 2021

DOl: https://doi.org/10.21203/rs.3.rs-74599/v3

License: (9) This work is licensed under a Creative Commons Attribution 4.0 International License. Read Full License 


\section{Abstract}

Objective: The WHO has stressed to regularly monitor the mental health of populations during the COVID19 pandemic. As a result, we conducted this study to examine anxiety and depression among recovered and recovering COVID-19 patients.

Subjects and Methods: An online survey was conducted using social media platforms. The study participants were COVID-19 infected individuals who had recovered or still were in the recovery phase from COVID-19. We collected information on demographics, clinical characteristics and physical complications of COVID-19. Anxiety and depressive symptoms were assessed using previously validated tools. Descriptive statistics and logistic regression were applied to analyze the data.

Results: $53.4 \%$ of respondents reported that they had a fear of getting COVID-19 again. Anxiety and depressive symptoms were present in $71.7 \%$ and $97.6 \%$ of respondents respectively. Both disorders were present in $71.3 \%$ of respondents. The respondents with shorter durations of physical symptoms ( 2 weeks) demonstrated less anxiety $(\mathrm{OR}=0.19 ; 95 \% \mathrm{Cl}$ : $0.05-0.67)$ and depression $(\mathrm{OR}=0.03 ; 95 \% \mathrm{Cl}$ : $0.01-0.37)$.

Conclusion: Anxiety and depression appear as common psychological complications in COVID-19 recovering and recovered patients. Longer durations of COVID-19 related physical symptoms were associated with an increased likelihood of anxiety and depression.

\section{Introduction}

Since the beginning of the 21st century, humanity has encountered and contained two major viral outbreaks of Coronavirus, namely Severe Acute Respiratory Syndrome (SARS) emerging in 2002 and Middle East Respiratory Syndrome (MERS) in 2012. ${ }^{1,27}$ COVID-19 is a novel infectious disease of the same Coronavirus family caused by a virus called SARS-COV-2. ${ }^{27}$ Starting in December 2019, COVID-19 spread very rapidly over the globe and was declared a pandemic by the World Health Organization (WHO). ${ }^{27}$ As of 6:49 PM CEST, 8 October 2021, the total number of COVID-19 infections had surpassed a figure of 241 million cases, resulting in more than seven hundred thousand deaths globally, and these infections are still increasing. ${ }^{27} \mathrm{~A}$ substantial number of COVID-19 patients are recovering and being discharged from hospital. ${ }^{2}$ Despite recovering from the infection, the patients experience a wide range of physical and mental health complications. ${ }^{3}$ Other than the delirium experienced during the quarantine and recovery phases, the incidence of various psychological disorders especially anxiety have been documented in previous studies. ${ }^{4-6}$ Several studies have analyzed the psychological issues of patients recovering from exposure to previous infectious diseases including SARS, MERS and EBOLA and observed various psychological complications. ${ }^{7-10}$ A systematic review and meta-analysis on SARS, MERS and COVID-19 patients in recovery reported a lower likelihood of serious mental illness overall. ${ }^{5}$ However, the same study indicated the possibility of anxiety and depressive symptoms among the COVID-19 individuals. ${ }^{5}$ Further research compared the psychological condition of MERS patients during 
their quarantined period supported by 4-6 months follow up data. Their findings reported reduction in anxiety prevalence from $7 \%$ to $3 \% .{ }^{11}$ Concerning COVID-19, an earlier study reported that anxiety and depressive symptoms were present in $34.72 \%$ and $28.47 \%$ of the patients respectively. ${ }^{12} \mathrm{~A}$ further study revealed that the scores for both disorders were significantly higher among COVID-19 patients than a healthy control group. ${ }^{13}$ The available data regarding psychological complications among COVID-19 recovered patients are not substantial, and yet the need for early intervention has been emphasized by earlier research studies. ${ }^{14,15}$ The purpose of this study therefore was to investigate psychological disorders among COVID-19 patients that have recovered and patients that are still in the recovery phase.

\section{Methods}

An online survey was conducted using Google survey forms. The link to the survey was made available to various COVID-19 recovered patients with access to social media. The patients were asked to participate in the survey and encouraged to send the survey link to further COVID-19 patient populations in recovery. Data collection was conducted in April 2020. All the relevant information regarding the purpose of the study, procedures, anonymity and ethical considerations were provided on the front page of the survey questionnaire. A statement of informed consent to participate in the study was included on the survey form. Only individuals who provided their written informed consent to participate were included in the study.

\section{Survey tools}

The survey tools comprised of two parts. The first part included demographic information such as age, gender, country, occupation and blood group. Further, we collected information regarding the COVID-19 test report, which included information about whether the patients were hospitalized or not, time spent thinking about COVID-19, recovery time, medical consultation, fear of getting COVID-19 again, physical complications during the recovery phase, and physical complications after recovery from COVID-19. The second part included the use of validated questionnaires. These included the Center for Epidemiological Studies Depression Scale (CES-D) to examine depressive symptoms ${ }^{16}$ and the Generalized Anxiety Disorder (GAD-7) scale to assess the anxiety levels of the patients. ${ }^{17}$

\section{Data Analyses}

Descriptive statistics of demographic variables, explanatory variables and outcome variables are presented as frequencies and percentages. Since both the outcome variables were dichotomous, binomial logistic regression was applied to predict the incidence of anxiety and depression based on explanatory variables. The alpha level was set at 0.05 for all inferential analyses.

\section{Results}


A total of 247 individuals completed the questionnaires (Table 1 ). Of the total respondents, $87.4 \%$ were female. Most of the respondents (55.1\%) were between 35 to 54 years of age. About $1 / 3(32.8 \%)$ of the respondents were from the healthcare profession. The majority of the respondents $(67.6 \%)$ were from the United States with the second largest number of respondents from the United Kingdom (12.9\%).

Table 1: Baseline parameters of participants $(\mathrm{N}=247)$ 


\begin{tabular}{|c|c|c|c|}
\hline \multicolumn{2}{|l|}{ Age } & Frequency & Percent \\
\hline \multirow[t]{4}{*}{ Categories } & Above 65 & 15 & 6.1 \\
\hline & Less than 35 years & 49 & 19.8 \\
\hline & Less than 55 & 136 & 55.1 \\
\hline & Less than 65 & 47 & 19.0 \\
\hline \multicolumn{2}{|l|}{ Gender } & Frequency & Percent \\
\hline \multirow[t]{2}{*}{ Categories } & Female & 216 & 87.4 \\
\hline & Male & 31 & 12.6 \\
\hline \multicolumn{2}{|l|}{ Occupation } & Frequency & Percent \\
\hline \multirow[t]{5}{*}{ Categories } & Business & 39 & 15.8 \\
\hline & Education & 34 & 13.8 \\
\hline & Healthcare & 81 & 32.8 \\
\hline & Other & 85 & 34.4 \\
\hline & Student & 8 & 3.2 \\
\hline \multicolumn{2}{|c|}{ Demographic characteristics: Country } & Frequency & Percent \\
\hline \multirow[t]{8}{*}{ Categories } & United States & 167 & 67.6 \\
\hline & United Kingdom & 32 & 12.9 \\
\hline & Australia & 2 & 0.8 \\
\hline & Europe & 17 & 6.8 \\
\hline & South America countries & 5 & 2.0 \\
\hline & Other North American countries & 7 & 2.8 \\
\hline & African countries & 7 & 2.8 \\
\hline & Asian countries & 10 & 4.3 \\
\hline
\end{tabular}


Of the 247 respondents who were infected with novel coronavirus, $212(85.8 \%)$ reported their condition status as negative and $35(14.2 \%)$ reported their condition status as positive. 212 respondents $(85.8 \%)$ reported that the symptoms were present for more than four weeks. More than half (53.4\%) reported that they had a fear of being infected by COVID-19 for a second time, $3.8 \%$ were indifferent and $13.4 \%$ had no fear of being re-infected. $58.3 \%$ of the total respondents reported that they spent more than 3 hours daily seeking COVID-19 related information. Detailed information on the clinical characteristics of the respondents is presented in Table 2.

Table 2: Clinical characteristics of participants

\begin{tabular}{|l|l|l|l|}
\hline \multicolumn{2}{|l|}{ Corona positive } & Frequency & Percent \\
\hline Categories & My reports are still positive & 35 & 14.2 \\
\cline { 2 - 4 } & Yes, but now my reports are negative & 212 & 85.8 \\
\hline Duration of symptoms & Frequency & Percent \\
\hline Categories & less than 2 weeks & 12 & 4.9 \\
\cline { 2 - 4 } & Less than 3 weeks & 17 & 6.9 \\
\cline { 2 - 5 } & Less than 4 weeks & 17 & 6.9 \\
\cline { 2 - 5 } & More than 4 weeks & 201 & 81.4 \\
\hline Fear that you will get COVID again & Frequency & Percent \\
\hline Categories & Maybe & 81 & 32.8 \\
\cline { 2 - 5 } & No & 34 & 13.8 \\
\cline { 2 - 5 } & Yes & 132 & 53.4 \\
\hline \multirow{5}{*}{ Daily time spent on COVID related information seeking } & Frequency & Percent \\
\hline Categories & Less than 1 hour & 42 & 17.0 \\
\cline { 2 - 5 } & Less than 2 hours & 36 & 14.6 \\
\cline { 2 - 5 } & Less than 3 hours & 25 & 10.1 \\
\cline { 2 - 5 } & More than 3 hours & 58.3 \\
\hline
\end{tabular}

As shown in Table 3, the symptoms of anxiety as revealed by the GAD-7 scale were observed in 177 $(71.7 \%)$ of the respondents. Depressive symptoms were present in 241 respondents (97.6\%). Only 5 
respondents (2\%) did not report any psychological problems (anxiety or depression). 176 (71.3\%) respondents testified the presence of both depression and anxiety. Based on the GAD-score, severe anxiety was present in $100(40.5 \%)$ respondents followed by moderate anxiety in $66(26.7 \%)$ respondents and mild anxiety in $49(19.8 \%)$ respondents. Only $32(13 \%)$ reported no anxiety.

Table 3: Psychological burden in respondents who have had COVID-19 infection

\begin{tabular}{|l|l|l|l|}
\hline Presence of Depression (>16) & Frequency & Percent \\
\hline Categories & Absent & 6 & 2.4 \\
\cline { 2 - 4 } & Present & 241 & 97.6 \\
\hline Presence of Any psychological burden (Depression or anxiety) \\
\hline Categories & No Depression or anxiety & 5 & 2.0 \\
\cline { 2 - 4 } & Any psychological issue present & 242 & 98.0 \\
\hline Presence of Both Depression and Anxiety & 71 & 28.7 \\
\hline Categories & Absent & 176 & 71.3 \\
\cline { 2 - 4 } & Both Depression and Anxiety present & 17 \\
\hline Severity of Anxiety (based on GAD-7) & 32 & 13.0 \\
\hline Categories & No Anxiety & 49 & 19.8 \\
\cline { 2 - 4 } & Only Mild anxiety & 66 & 26.7 \\
\cline { 2 - 4 } & Moderate anxiety & 100 & 40.5 \\
\cline { 2 - 4 } & Severe anxiety & & \\
\hline
\end{tabular}

Results of the logistic regression analyses outlined the likelihood of the incidence of anxiety, depression and any psychological disorder (depression or anxiety) based on various predictor variables (Table 4). The variables including younger age range ( $<35$ years), gender, employment status and time spent seeking COVID-19 related information did not add significantly to the model. However, the duration of COVID-19 related physical symptoms was significantly related to the incidence of anxiety, depression and psychological issues. The patients having shorter duration of COVID-19 related symptoms ( 2 weeks) had lesser likelihood of experiencing anxiety $(\mathrm{OR}=0.19 ; 95 \% \mathrm{Cl}: 0.05-0.67)$ and depression $(\mathrm{OR}=0.03$; $95 \% \mathrm{Cl}: 0.01-0.37)$ than those having longer duration COVID-19 related symptoms. 
Table 4: Logistic regression: Odds ratio for having Psychological issues (Logistic regression analysis)

\begin{tabular}{|c|c|c|c|c|}
\hline & Presence of Anxiety & $\begin{array}{l}\text { Presence } \\
\text { Depression }\end{array}$ & of & $\begin{array}{lr}\text { Presence of } & \text { any } \\
\text { psychological issue } \\
\text { (Depression } \\
\text { anxiety) }\end{array}$ \\
\hline Jries & 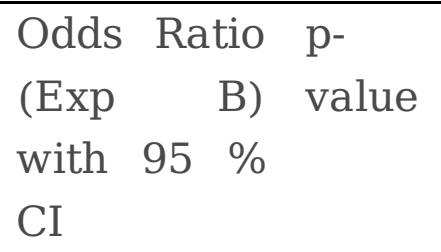 & $\begin{array}{l}\text { Odds } \\
\text { Ratio (Exp } \\
\text { B) with } 95 \\
\text { \% CI }\end{array}$ & $\begin{array}{l}\mathrm{p}- \\
\text { value }\end{array}$ & $\begin{array}{lrll}\text { Odds } & \text { Ratio } & \text { p- } \\
\text { (Exp } & \text { B) } & \text { value } \\
\text { with } & 95 & \% & \\
\text { CI } & & & \end{array}$ \\
\hline $\begin{array}{l}\text { er age } \\
\text { years) }\end{array}$ & $\begin{array}{l}0.35(0.12-0.07 \\
1.06)\end{array}$ & $\begin{array}{l}0.19(0.01 \\
-2.93)\end{array}$ & 0.24 & $\begin{array}{l}0.07(0.01-0.10 \\
1.70)\end{array}$ \\
\hline e gender & $\begin{array}{lll}0.39 & (0.13- & 0.09 \\
1.16) & & \\
\end{array}$ & $\begin{array}{l}2.56(0.27 \\
-24.21)\end{array}$ & 0.41 & $\begin{array}{l}3.09(0.27-0.36 \\
35.03)\end{array}$ \\
\hline Unemployed & $\begin{array}{l}2.25(0.42-0.34 \\
12.08)\end{array}$ & $\begin{array}{l}2.58(0.01 \\
-3.69)\end{array}$ & 0.25 & 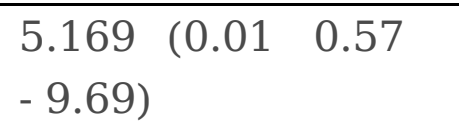 \\
\hline $\begin{array}{l}\text { r duration of } \\
\text { )-19 related } \\
\text { al symptoms } \\
\text { 'eeks) }\end{array}$ & $\begin{array}{l}0.19 \text { (0.05- } 0.01 * \\
0.67)\end{array}$ & $\begin{array}{l}0.03(0.01 \\
-0.37)\end{array}$ & $0.006 *$ & $\begin{array}{l}0.02(0.01-0.004 * \\
0.27)\end{array}$ \\
\hline $\begin{array}{l}\text { than } 3 \text { hours spent } \\
\text { :OVID-19 related } \\
\text { ation seeking }\end{array}$ & $\begin{array}{l}1.72(1.43-0.28 \\
2.33)\end{array}$ & $\begin{array}{l}1.28(0.03 \\
-2.47)\end{array}$ & 0.23 & $\begin{array}{l}0.51(0.04-0.47 \\
5.65)\end{array}$ \\
\hline
\end{tabular}

*Statistically significant based on 2-tailed p-value

\section{Discussion}

Resulting from increases in the COVID-19 pandemic, the World Health Organization has stressed the importance of regularly monitoring and managing the mental health of patients infected with COVID19. ${ }^{18}$ There is evidence regarding the psychological impact of COVID-19 in the general community, however data regarding infected and recovering patients is severely limited. ${ }^{19,20}$ The present study was undertaken to identify any psychological issues that may affect COVID-19 patients. The study focused on two psychological variables: the presence of anxiety disorder and depression. The findings of the study could provide health professionals with important information about the effects and prevalence of 
anxiety disorder and depression among COVID-19 patients. The data obtained may also be useful in designing and planning interventions for coping with mental health issues in recovering COVID-19 patients.

In our sample, $85.8 \%$ had recovered from the infection, yet, $14.2 \%$ were still infected with the disease. Our key findings were that signs of anxiety and depression were present in most patients. Also, the prevalence of depression (97.6\%) was higher than the prevalence of anxiety (71.7\%). Our study shows higher prevalence of both disorders than an earlier web-based study on COVID-19 patients, in which depression and anxiety were present in $21 \%$ and $15 \%$ patients respectively. ${ }^{21}$ Another study reported extremely severe symptoms of anxiety and depression existed among $97.29 \%$ and $54.29 \%$ patients respectively. ${ }^{22}$ In contrast, a Chinese study documented relatively lesser prevalence of both disorders. ${ }^{23}$ Furthermore, prevalence rates of depression and anxiety found in our study are higher than a previous study on 144 patients, ${ }^{12}$ and the study reported that age and gender were significant predictors of anxiety and depression in COVID-19 patients. However, in our study, logistic regression confirmed that the variables gender, age, employment status and time spent on thinking about COVID-19 were not significantly associated with the incidence of anxiety and depression. The only significant predictor of anxiety and depression was the duration of COVID-19 related physical symptoms. It can be interpreted from the logistic regression results that patients having physical symptoms for more than two weeks were more likely to have incidences of anxiety and depression. The possible causes of these outcomes might be the fear of COVID-19 related death, prolonged isolation or spread of fear and uncertainty through social media. A similar study revealed that anxiety and depressive mood were linked with the loss of smell and taste but not linked with other physical symptoms such as coughing, fever or shortness of breath. ${ }^{24}$

\section{Limitations and future directions}

Our study has some limitations. Firstly, the survey language was English which may be a barrier for some people to participate and understand the survey questions. Moreover, the data does not represent the patients who do not have access to social media and consequently are not social media active. Secondly, no systematic sampling method was used to recruit the participants and therefore the sampled data could contain sampling bias. In addition, the sample size of 247 includes $87.4 \%$ of females and only $12.6 \%$ males. This unevenly distributed sample represents females more than the males. Thirdly, the patients with severe infection could not complete the survey questionnaire. In addition, existing morbidities were not assessed in our survey and these may act as confounding variables and affected study results.

Despite having the number of limitations, to our knowledge, this study is the first of its kind that has used asocial media platform to communicate the psychological impact of COVID-19 infection in recovered and recovering patients. Previous studies have surveyed the psychological impact during the COVID-19 lockdown, but those studies were limited to uninfected and general populations. ${ }^{20,25}$ In future studies, larger and more systematic data collection strategies should be devised to reach a more diverse population; for instance, patients not participating in social media activities. 


\section{Conclusion}

Symptoms of severe anxiety and depression were present in the majority of COVID-19 infected individuals. Shorter durations of infection of the physical symptoms of COVID-19 significantly decreases the likelihood of the incidence of depressive symptoms and anxiety. Since this study has reported only initial findings of the psychological impact of patients who have had, and who are recovering from COVID-19, larger systematic assessments will help formulate comprehensive interventions for recovering COVID-19 patients.

\section{Declarations}

Ethical consideration: All methods used in the study involving human participants were in accordance with the 1964 Helsinki declaration and its later amendments or comparable ethical standards.

Informed consent: Informed consent was obtained from all individual participants included in the study.

\section{Author's contribution}

Conceptualization: Vikesh Kumar, Mohit Varshney, Amandeep Singh; Methodology: Vikesh Kumar, Harmandeep Singh, Mohit Varshney, Amandeep Singh; Formal analysis and investigation: Mohit Varshney, Harmandeep Singh, Vikesh Kumar; Writing - original draft preparation: Harmandeep Singh, Mohit Varshney, Julien S. Baker; Writing - review and editing: Harmandeep Singh, Mohit Varshney, Julien S. Baker, Amandeep Singh; Supervision: Amandeep Singh, Julien S. Baker

\section{References}

1. Desforges M, Le Coupanec A, Dubeau P, Bourgouin A, Lajoie L, Dubé M, et al. Human Coronaviruses and Other Respiratory Viruses: Underestimated Opportunistic Pathogens of the Central Nervous System? Viruses [Internet]. 2020 Jan [cited 2020 Aug 3];12(1):14. Available from: https://www.mdpi.com/1999-4915/12/1/14

2. WHO. Coronavirus [Internet]. [cited 2021 Oct 17]. Available from: https://www.who.int/westernpacific/health-topics/coronavirus

3. Rajkumar RP. COVID-19 and mental health: A review of the existing literature. Asian J Psychiatr [Internet]. 2020 Aug [cited 2020 Aug 3];52:102066. Available from:

https://www.ncbi.nlm.nih.gov/pmc/articles/PMC7151415/

4. Holmes EA, O'Connor RC, Perry VH, Tracey I, Wessely S, Arseneault L, et al. Multidisciplinary research priorities for the COVID-19 pandemic: a call for action for mental health science. Lancet Psychiatry. 2020;7(6):547-60. 
5. Rogers JP, Chesney E, Oliver D, Pollak TA, McGuire P, Fusar-Poli P, et al. Psychiatric and neuropsychiatric presentations associated with severe coronavirus infections: a systematic review and meta-analysis with comparison to the COVID-19 pandemic. The Lancet Psychiatry [Internet]. $2020 \mathrm{Jul} 1$ [cited 2020 Aug 3];7(7):611-27. Available from:

http://www.sciencedirect.com/science/article/pii/S2215036620302030

6. Brooks SK, Webster RK, Smith LE, Woodland L, Wessely S, Greenberg N, et al. The psychological impact of quarantine and how to reduce it: rapid review of the evidence. The Lancet [Internet]. 2020 Mar 14 [cited 2020 Aug 3];395(10227):912-20. Available from:

https://www.thelancet.com/journals/lancet/article/PIIS0140-6736(20)30460-8/abstract

7. Lee AM, Wong JG, McAlonan GM, Cheung V, Cheung C, Sham PC, et al. Stress and Psychological Distress among SARS Survivors 1 Year after the Outbreak. Can J Psychiatry [Internet]. 2007 Apr 1 [cited 2020 Aug 3];52(4):233-40. Available from: https://doi.org/10.1177/070674370705200405

8. Hawryluck L, Gold WL, Robinson S, Pogorski S, Galea S, Styra R. SARS Control and Psychological Effects of Quarantine, Toronto, Canada. Emerg Infect Dis [Internet]. 2004 Jul [cited 2020 Aug 3];10(7):1206-12. Available from: https://www.ncbi.nlm.nih.gov/pmc/articles/PMC3323345/

9. Kim H-C, Yoo S-Y, Lee B-H, Lee SH, Shin H-S. Psychiatric Findings in Suspected and Confirmed Middle East Respiratory Syndrome Patients Quarantined in Hospital: A Retrospective Chart Analysis. Psychiatry Investig. 2018 Apr;15(4):355-60.

10. Yadav S, Rawal G. The Current Mental Health Status of Ebola Survivors in Western Africa. J Clin Diagn Res [Internet]. 2015 Oct [cited 2020 Aug 3];9(10):LA01-2. Available from:

https://www.ncbi.nlm.nih.gov/pmc/articles/PMC4625262/

11. Jeong H, Yim HW, Song Y-J, Ki M, Min J-A, Cho J, et al. Mental health status of people isolated due to Middle East Respiratory Syndrome. Epidemiol Health [Internet]. 2016 Nov 5 [cited 2020 Aug 3];38. Available from: https://www.ncbi.nlm.nih.gov/pmc/articles/PMC5177805/

12. Kong X, Zheng K, Tang M, Kong F, Zhou J, Diao L, et al. Prevalence and Factors Associated with Depression and Anxiety of Hospitalized Patients with COVID-19. medRxiv [Internet]. 2020 Apr 5 [cited 2020 Aug 3];2020.03.24.20043075. Available from:

https://www.medrxiv.org/content/10.1101/2020.03.24.20043075v2

13. Yang L, Wu D, Hou Y, Wang X, Dai N, Wang G, et al. Analysis of psychological state and clinical psychological intervention model of patients with COVID-19. medRxiv [Internet]. 2020 Mar 24 [cited 2020 Aug 3];2020.03.22.20040899. Available from:

https://www.medrxiv.org/content/10.1101/2020.03.22.20040899v1

14. Galea S, Merchant RM, Lurie N. The Mental Health Consequences of COVID-19 and Physical Distancing: The Need for Prevention and Early Intervention. JAMA Intern Med [Internet]. 2020 Jun 1 [cited 
2020 Aug 3];180(6):817-8. Available from:

https://jamanetwork.com/journals/jamainternalmedicine/fullarticle/2764404

15. Xiang Y-T, Yang Y, Li W, Zhang L, Zhang Q, Cheung T, et al. Timely mental health care for the 2019 novel coronavirus outbreak is urgently needed. Lancet Psychiatry. 2020;7(3):228-9.

16. Radloff LS. The CES-D Scale: A Self-Report Depression Scale for Research in the General Population. Applied Psychological Measurement [Internet]. 1977 Jun 1 [cited 2020 Aug 3];1(3):385-401. Available from: https://doi.org/10.1177/014662167700100306

17. Spitzer RL, Kroenke K, Williams JBW, Löwe B. A brief measure for assessing generalized anxiety disorder: the GAD-7. Arch Intern Med. 2006 May 22;166(10):1092-7.

18. WHO. Mental-health-considerations.pdf [Internet]. [cited 2021 Oct 17]. Available from: https://www.who.int/docs/default-source/coronaviruse/mental-health-considerations.pdf

19. Luo W, Yu H, Gou J, Li X, Sun Y, Li J, et al. Clinical Pathology of Critical Patient with Novel Coronavirus Pneumonia (COVID-19). 2020 Feb 27 [cited 2020 Aug 3]; Available from: https://www.preprints.org/manuscript/202002.0407/v2

20. Varshney M, Parel JT, Raizada N, Sarin SK. Initial psychological impact of COVID-19 and its correlates in Indian Community: An online (FEEL-COVID) survey. PLOS ONE [Internet]. 2020 May 29 [cited 2020 Aug 3];15(5):e0233874. Available from: https://journals.plos.org/plosone/article? id=10.1371/journal.pone.0233874

21. Zhang J, Lu H, Zeng H, Zhang S, Du Q, Jiang T, et al. The differential psychological distress of populations affected by the COVID-19 pandemic. Brain Behav Immun [Internet]. 2020 Jul [cited 2020 Aug 3];87:49-50. Available from: https://www.ncbi.nlm.nih.gov/pmc/articles/PMC7156946/

22. Moayed MS, Vahedian-Azimi A, Mirmomeni G, Rahimi-Bashar F, Goharimoghadam K, Pourhoseingholi MA, et al. Depression, Anxiety, and Stress Among Patients with COVID-19: A CrossSectional Study. Adv Exp Med Biol. 2021;1321:229-36.

23. Dai L-L, Wang X, Jiang T-C, Li P-F, Wang Y, Wu S-J, et al. Anxiety and depressive symptoms among COVID-19 patients in Jianghan Fangcang Shelter Hospital in Wuhan, China. PLOS ONE [Internet]. 2020 Aug 28 [cited 2021 Oct 17];15(8):e0238416. Available from:

https://journals.plos.org/plosone/article?id=10.1371/journal.pone. 0238416

24. Speth MM, Singer-Cornelius T, Oberle M, Gengler I, Brockmeier SJ, Sedaghat AR. Mood, anxiety and olfactory dysfunction in COVID-19: evidence of central nervous system involvement? Laryngoscope [Internet]. 2020 Jul 2 [cited 2020 Aug 3]; Available from:

https://www.ncbi.nlm.nih.gov/pmc/articles/PMC7361512/ 
25. Chakraborty K, Chatterjee M. Psychological impact of COVID-19 pandemic on general population in West Bengal: A cross-sectional study. Indian Journal of Psychiatry [Internet]. 2020 May 1 [cited 2020 Aug 3];62(3):266. Available from: http://www.indianjpsychiatry.org/article.asp?issn=00195545 ;year $=2020$; volume $=62$;issue $=3$; spage $=266$;epage $=272$; aulast $=$ Chakraborty;type $=0$. 